\title{
Materia dispuesta: entre la pirámide y el axolotl*
}

\section{Paula Andrea Marín Colorado**}

\section{Resumen}

En este artículo se presenta un acercamiento a la novela Materia dispuesta, del escritor mexicano Juan Villoro. En esta aproximación analítica se pretende dilucidar la conexión entre la obra literaria y el medio en el que se gesta, así como con el momento histórico recreado en la anécdota de la novela (el terremoto ocurrido en Ciudad de México en 1985); lo anterior con el objetivo de establecer la propuesta estética del autor en esta obra y su relación con la visión que construye Materia dispuesta sobre los procesos de Modernidad y Postmodernidad en Latinoamérica. Para tal propósito se recurrirá a las investigaciones literarias y sociológicas de Mijail Bajtín, Zigmunt Bauman, Carlos Monsiváis y Octavio Paz, entre otros.

\section{Palabras claves}

Modernidad, Postmodernidad, axiología, novela de desarrollo, identidad mexicana.

* Resultado de investigación realizado en el Seminario Andrés Bello, Instituto Caro y Cuervo.

** Licenciada en Lingüística y Literatura con énfasis en Literatura (Universidad Distrital), Candidata a título de Magíster en Literatura Hispanoamericana (Instituto Caro y Cuervo). paulanmc@hotmail.com. 


\section{Abstract}

In this article it is showed an approach to the novel Materia Dispuesta, by the Mexican writer Juan Villoro. This analytical approach pretends to elucidate the connection between the literary piece and the environment in which it is created, likewise the historical moment represented in the novel's anecdote (the earthquake happened in Mexico City in 1985). The above-mentioned has the objective of establishing the author's aesthetic proposal in this piece and its relationship with the vision that Materia Dispuesta builds on the processes of Modernity and Post modernity in Latin America. For that purpose, it will appeal to the literary and sociological investigations by Mijail Baltin, Zigmunt Baugman, Carlos Monsivais and Octavio Paz between others.

\section{Key words}

Modernity, Post modernity, axiology, novel of development, Mexican identity.

"La única patria verdadera se asume sin posar para la mirada ajena".

Juan Villoro.

“¿Podía ser el mundo tan distinto a sus promesas?”.

Juan Villoro (Materia dispuesta).

\section{Introducción}

Materia dispuesta ${ }^{8}$, segunda novela del escritor mexicano Juan Villoro (México, 1956), narra la historia de Mauricio Guardiola desde su nacimiento hasta que 
cumple veintiocho años (1957-1985); ambos acontecimientos corresponden con la fecha de los terremotos que sacudieron la ciudad de México en los años referenciados. El nacimiento de Mauricio Guardiola coincide con la graduación de su padre como arquitecto; de aquí en adelante, la narración va a estar centrada en la relación de Jesús Guardiola y su hijo, a través del contraste entre sus dos vidas, sus dos caracteres. Jesús Guardiola ingresa, a finales de los años sesenta, en la Escuela Mexicana, un grupo de arquitectos cuyo propósito es recuperar la tradición prehispánica, vinculándola a la urbe moderna; a partir de este momento, Jesús Guardiola intentará contagiar de su entusiasmo a Mauricio, pero la actitud de éste siempre será de total escepticismo frente a una tradición que parece incuestionable.

Materia dispuesta se propone como una obra enmarcada en la recreación de un momento histórico en el que se producen las críticas más fuertes al proyecto de la Modernidad (período de Posguerra), las cuales desencadenarán una serie de procesos culturales que propondrán una manera alterna de afrontar la realidad: el "Tercer Mundo", se propone desde Europa como el territorio de nuevas utopías y América Latina emprende la "recuperación" de su"singularidad identitaria". Teniendo en cuenta lo anterior, se propone como hipótesis de sentido la siguiente: Mauricio Guardiola como personaje que encarna la transición de una época a otra (Modernidad a Postmodernidad), permite reconocer la complejidad de la realidad Latinoamericana, sus procesos de hibridación cultural, de épocas que se yuxtaponen en un territorio inestable; esta transición implicará la crítica de la tradición, pero también la coexistencia de valores modernos y lo que se comienza a dibujar como una mentalidad postmoderna.

Dentro de la crítica que propone Mauricio Guardiola al proyecto moderno, la posibilidad de lo residual, de la existencia de lo disperso, adquirirá validez, pero también el vislumbramiento de una nueva especie de totalidad que permita vincular lo fragmentario, más allá de una simple suma de las partes. Mauricio Guardiola se propone en Materia dispuesta, como un personaje configurado a través de lo que Bajtín (1985) denomina"novela de desarrollo del hombre", en cuanto a su ubicación ética entre el límite de dos épocas, lo 
cual lo lleva a proponerse como un nuevo tipo de hombre estrechamente relacionado con el devenir histórico y, específicamente, con lo que significó para México el terremoto ocurrido el 19 de septiembre de 1985 en cuanto a la configuración de una naciente sociedad civil.

\section{Mauricio Guardiola: el héroe novelesco más allá del apocalipsis}

Ser "materia dispuesta" es la condición que relaciona más estrechamente las vidas de Mauricio Guardiola y Jesús Guardiola. Desde el título de la novela se hace referencia a esta condición de la existencia, la cual direcciona el sentido de la obra a través del contraste entre los dos personajes mencionados (padre e hijo); la primera imagen que aparece en la obra para ilustrar dicho contraste son los dos lados que tiene una toalla: el rasposo y el suave. Mauricio identificará a su padre (y a su hermano mayor: Carlos) con el lado rasposo, mientras que él se ubicará en el suave: "Mi padre siempre usó el lado rasposo de la toalla. Si algo definía su carácter era la furia para frotar y admirar su carne enrojecida. [...] Mamá suavizaba toallas secretas para ella y para mí. Crecí del lado opuesto, algo que en la esotérica valoración de las telas familiares significaba dejarse llevar por la vida fácil" (16-17). A partir de lo anterior, puede proponerse una interpretación: mientras que Jesús Guardiola se configurará como un personaje que presenta una axiología moderna, Mauricio encarnará la emergencia de una axiología postmoderna9 .

El término "axiología" se puede entender a partir de los planteamientos de Mijail Bajtín para el análisis de la novela: "La forma artística es la forma del contenido, pero realizada por completo en base al material y sujeta a él. Por ello, la forma debe entenderse y estudiarse en dos direcciones: 1) desde dentro del objeto estético puro, como forma arquitectónica orientada axiológicamente hacia el contenido (acontecimiento posible), y relacionada con éste, 2) desde dentro del conjunto material y compositivo de la obra: es el estudio de la técnica de la forma” (Mijail Bajtín [1975], Teoría y estética de la novela (Madrid: Taurus, 1989) 60). Lo axiológico, aquí, hace referencia a los valores cualitativos que materializa la obra a través de sus diversos elementos: anécdota (acontecimientos), personajes, tiempo-espacio,... (sigue) 
Zigmunt Bauman establece la diferencia entre la Modernidad sólida y lo que él denomina como Modernidad líquida -concepto equiparable a lo que otros teóricos denominan como Postmodernidad- para explicar el paso de una época a otra. La Modernidad sólida hace referencia a ese proceso histórico que se lleva a cabo desde el Renacimiento y que adquiere características definidas en el siglo XVIII con el proyecto ilustrado. Las técnicas científicas o políticas, permiten estructurar una visión del hombre como dominador de las cosas; la técnica racional eleva el individuo a la categoría del que puede hacerlo todo, transformar productivamente lo que lo rodea. El dinero y el intelecto otorgan al hombre una voluntad de poder que no reconoce obstáculos insuperables y que instaura el ideal del progreso; lo anterior lleva a la caracterización de un rasgo de la mentalidad burguesa: la ambición que lo lleva a ampliar su poderío económico y político, pues aunque no pertenezca a una familia noble, sabe que su condición ya no le impide aspirar al poder, como era la tradición.

La Modernidad líquida, por su parte, es la etapa actual de la Modernidad, en la cual los valores defendidos por la Modernidad sólida se han transformado

9 (viene) ...lenguaje, modo de narrar; sin embargo, dichos valores no se pueden confundir con los que son propios del creador de la obra, pues el objeto estético exige una segunda valoración sobre esos aspectos que dirigen la vida de todos los seres humanos (el cognitivo y el ético): el acto creativo cultural "tiene que ver siempre con algo ya valorado y más o menos responsable, ante lo que se tiene que adoptar ahora, de manera responsable, una posición valorativa. Así, el acto cognitivo encuentra, ya elaborada en conceptos, la realidad [...]; pero, lo que es más importante, la encuentra valorada y organizada con anterioridad por la acción ética (práctica, social, política)" (Bajtín, Teoría, 31).

En ese sentido, la forma estética está configurada a partir de una actitud ante lo cognitivo o ético; el autor-creador realiza un distanciamiento respecto a la realidad, denominado por Bajtín como función de "aislamiento", es decir, como una superación de la subjetividad que permite también superar la realidad inmediata, elaborando libremente los materiales de la organización compositiva y valorativa de la obra, la cual, sin embargo, remite a esa realidad, pero para proponer una visión del mundo particular, una posición moral particular ante la existencia, ante la Historia; esa visión particular se puede leer en todos los elementos de la obra, especialmente en el sistema de personajes. Cada obra literaria construye un sistema axiológico particular, problematiza valores que son encarnados de manera tangible en los personajes, en sus acciones, en sus elecciones y resoluciones, configurando una forma singular de interpretar la realidad. 
para dar paso a una "época de la instantaneidad", en la que se busca"gratificación evitando las consecuencias, y particularmente las responsabilidades que esas consecuencias pueden involucrar" (Bauman, 2006, 137) La Modernidad líquida o Postmodernidad presenta el reto de superar el orden clásico de la Modernidad sólida, las clasificaciones que promovían la desigualdad; ahora es posible relativizar las absolutizaciones, pero no invisivilizarlas, pues las verdades sobre las que funciona la sociedad siguen existiendo e imponiendo su lógica. La Postmodernidad permite cuestionar estas verdades, reinterpretarlas, analizando las relaciones en las que éstas se legitiman, pero teniendo en cuenta las implicaciones morales que esto representa:

La nuestra es una versión privatizada de la modernidad, en la que el peso de la construcción de pautas y la responsabilidad del fracaso caen primordialmente sobre los hombros del individuo. La licuefacción debe aplicarse ahora a las pautas de dependencia e interacción, porque les ha tocado el turno. Esas pautas son maleables hasta un punto jamás experimentado ni imaginado por las generaciones anteriores, ya que, como todos los fluidos, no conservan mucho tiempo su forma [...]. Mantener la forma de los fluidos requiere muchísima atención, vigilancia constante y un esfuerzo perpetuo. (Bauman, 2006, 13)

Para Bauman, el reto de la Postmodernidad reside en recuperar el impulso moral del individuo a través de lo que podría denominarse como una mentalidad postmoderna; la responsabilidad del individuo postmoderno estaría en reconocer que la mayoría de edad kantiana aún resulta vigente, pero, sobre todo, necesaria para combatir la anestesia racional que promulga la mentalidad posmoderna más conformista, la cual propone la irracionalidad como bandera, "haciéndonos vulnerables ante cualquier idea, por débil que sea" (Marina, 2000, 52), postergando de nuevo la posibilidad de pensar por sí mismos y constituirnos como auténticos seres morales. En ausencia de proyectos políticos, en medio de la "crisis de valores" que se presenta en la Postmodernidad, la nueva mentalidad se propone como un proyecto moral constituyente de un sujeto que acepte el sin sentido postmoderno, 
la incertidumbre de lo real que siempre es insoslayable, y la cual no puede controlarse por la obediencia a normas externas que anulan la capacidad y responsabilidad moral del individuo.

En Materia dispuesta, Mauricio Guardiola se presenta como un personaje en formación que asume el cambio de la Modernidad sólida a la Modernidad líquida, en tanto, al igual que su padre -aunque en un sentido alterno, según se verá más adelante-, se acepta como “materia dispuesta"10 , es decir, si en un comienzo aspira a ser como su padre, luego se da cuenta de que su ventaja está precisamente en ser diferente a él, a su hermano -y a su amigo Pancho-: "Mi padre y Carlos disponían de una fuerza incompatible, pero yo podía torcer sus destinos, conducirlos, comer sus desperdicios. En el momento menos pensado [... ] sería el dueño de la ruta" (72). Mauricio Guardiola, en un primer momento, se asume como un ser sin destino -a diferencia de su padre

Su padre afirma que es "materia dispuesta" cuando Roberta Archer -quien se convertirá en la segunda esposa de Jesús-le dice que teme a los asaltos y le pide que la acompañe a su carro; Jesús le confirmará su disponibilidad ilimitada para hacerlo -o hacer cualquier otra cosa-. Sin embargo, esta expresión de su padre trascenderá el plano superficial en Mauricio, pues en Jesús, dichas palabras sólo registran otra marca de su axiología inconsistente (maleable por sus pasiones, aunque en su exterior parezca lo contrario, dado su compromiso con su trabajo-Patria), pero en su hijo revelarán otra manera de enfrentar la cambiante e inestable realidad actual.

Por su parte, Pancho, amigo de Mauricio, también se configurará a partir de una axiología inconsistente; su ambivalencia reside en poder amoldarse a todas las situaciones sin estar convencido de ninguna: es el niño que consigue tener entre sus labios el sexo viril del dueño de una vulcanizadora de quien Mauricio se había enamorado y, al mismo tiempo, es el niño que provoca el enamoramiento de la niña más bella de Terminal Progreso -a quien rechaza-, y el muchacho que saca provecho de las mujeres mayores como acompañante; es el joven que ingresa en la Juventud Comunista y luego pasa a un grupo de acción directa; por último, es el hombre que decide ser actor y participa en la obra Abraxas, la cual representa lo "mexicano" en el exterior. A diferencia de Mauricio, Pancho es el personaje que puede comprometerse con cualquier cosa y que por eso mismo puede abandonarla con facilidad; su compromiso es en realidad un no-compromiso, mientras que en Mauricio el no-compromiso está en la raíz de su axiología y corresponde con su posición de testigo -como se explicará más adelante-. 
y su hermano-, un ser al que no le aguardan grandes hazañas, pero luego se percata de que"todo era materia dispuesta, su vida se ordenaba con la fuerza reveladora de las confusiones" (188); al ver su vida en un instante como una unidad nítida, Mauricio descubre que su existencia también se constituye bajo una propia noción de destino -aunque distinta a la de su padre y su hermano-, que todo lo que le había sucedido, él lo había buscado como una manera de apartarse del camino mostrado por Jesús y Carlos Guardiola. "La fuerza reveladora de las confusiones" que le permite a Mauricio revelar su alterna concepción de destino, es una fuerza elegida por cada ser humano, no por una entidad extraterrena o institucional (la familia, la Iglesia, el Estado); la confusión (los acontecimientos, el azar) permite otorgar sentido a la vida, de la misma manera que la casualidad se convierte en causalidad cuando se reconstruye la vida de algún ser humano, otorgándole una lógica artificial a sus actos y sus efectos.

Carlos y Jesús Guardiola poseen destino en tanto su carácter los convierte en seres claramente conscientes de lo que desean y de lo que deben hacer para lograrlo, para progresar; su destino real es construir uno propio, es adelantarse al "destino" (axiología moderna), buscar los medios para alcanzar sus objetivos; en Mauricio, en cambio, el destino se configura a partir de experiencias mediadas por la imaginación: "También había materia y sustancia en lo no visto. [... ] La materia informe también tenía una atractiva resonancia sexual; ninguna expresión mejor para los deseos donde la imaginación estaba más comprometida que la piel. [...] Tenían más relieve que sus pocos escarceos reales" (202-203). La imaginación y las confusiones como materia de interpretaciones configuran, entonces, la noción de destino de Mauricio: “El lado áspero para quienes construían y se adelantaban al destino; el lado suave para los testigos que recogían las porciones dispersas, rotas" (311), no lo sólido, lo ya formado, sino apenas lo dispuesto, lo que permite construir un sentido propio de la vida desde la posición de testigo, es decir, de aquel que mantiene cierta distancia frente a su realidad desde la cual percibe las inconsistencias (lo fragmentario) y las redes que configuran su mundo, pero también esta posición le permite testimoniar la realidad como irreductible a una sola verdad; de allí que el desenlace de la historia coincida con la 
decisión de Mauricio de estudiar video y de su trabajo como camarógrafo en un programa de televisión: la cámara como un "azar favorable", como el elemento que materializa su posición de testigo.

La noción de destino como construcción de un camino propio con base en esfuerzos individuales, se desdibuja en Mauricio, quien al ubicarse en "el lado suave de la toalla" y asumirse como testigo, acepta la vida como incertidumbre, como fragmentación, pero con la responsabilidad de registrar esa dispersión, la degradación de un mundo sólido que le habían asegurado en su infancia. Mauricio encarna, de esta manera, la transición de una época a otra: a través de la construcción paulatina de una visión lúcida frente su generación anterior, Mauricio Guardiola configura otras formas de leer su realidad, un mundo a puertas de desaparecer, pero también del cual se pueden conservar algunos elementos que permitan asumir una responsabilidad moral en la Postmodernidad emergente.

\section{El axolotl convertido en salamandra}

Respecto a lo explicado anteriormente, resulta significativo el hecho que el modo de narrar en Materia dispuesta se constituya a partir de dos momentos: en la primera mitad de la novela, la narración está a cargo del personaje principal (Mauricio Guardiola); la voz narrativa reconstruye los acontecimientos desde la subjetivación de la experiencia del protagonista, pero justo en la mitad de la obra, la narración fluctúa entre un narrador en primera persona y uno omnisciente. La segunda mitad de la novela será narrada a través de la voz de un narrador-testigo que presentará los acontecimientos de manera distanciada, respecto al modo de narrar anterior, aunque bajo la perspectiva de Mauricio.

Esta fluctuación narrativa coincide con el cumpleaños número quince de Mauricio, con su situación de adolescente, su realidad anfibia que lo hace tener un pie en la niñez y otro en la edad adulta; Mauricio se presenta, así, como un desconocido para ese otro Mauricio que empieza a aflorar: "Tenía una inquietud fundamental, buscaba un centro que, sin saber cómo, se le había perdido. Mis sándwiches de tres mostazas, mis historias galácticas, las 
fantasías eróticas en las que intervenía una columna de fuego y la resistente ropa de azafata de Rita, eran intolerables para Mauricio; en su inseguro afán de perfección, en su ajuste a una realidad desconocida, temía que su camisa se manchara de sudor en las axilas [...]. A veces [...] rezaba para no ser él" (140). Y unas páginas más adelante: "Mauricio y yo no coincidíamos en nada [...]. Yo me divertía pateando un charco de agua y Mauricio siempre quería algo impreciso pero definitivamente distinto; se asustaba de lo que le gustaba y al mismo tiempo despreciaba mis ganas de extender los brazos y tronar la boca como un aeroplano" (157).

Su situación de extraño para sí mismo lo obliga a distanciarse de sí: para alcanzar el mundo como una realidad concreta, para aislar su realidad de situaciones sólo imaginadas, de sucesos que tenían más lugar en su mente que en el mundo real durante su niñez, el narrador supera su propia subjetividad a través de una voz narrativa que busca materializar la experiencia vital otorgándole una forma que permita entrever una totalidad posible, un mundo que posibilite la pertenencia a él, un actuar en él; la narración"objetivada" señala la intención del personaje de integrarse al mundo, abandonar un narcisismo o una especie de principio de placer para vincular a su existir el principio de realidad. Después de la mitad de la novela, las experiencias de Mauricio tendrán más que ver con lo tangible, cobrarán materia en la realidad y permitirán concebir al personaje como un actor en su mundo ${ }^{11}$.

Este cambio en el personaje se relaciona con la figura de los axolotl o ajolotes ${ }^{12}$ que aparecen en la novela. En el momento inmediatamente anterior

11 Este aspecto es tangible en el hecho que durante este intervalo Mauricio tenga su primera experiencia sexual (con un hombre furtivo y luego con una prostituta), pertenezca por un tiempo a la Juventud Comunista por influjo de su amigo Pancho, ingrese en un grupo de teatro, entre en el medio laboral primero como conductor y luego como camarógrafo y conviva por un tiempo con una mujer.

12 Los ajolotes son una clase de anfibios, estado larvario de la salamandra marrón; poseen branquias, aletas y cola, características que les permiten habitar en las aguas como una clase de peces. La mayoría de estos animales no logra llegar a su estado adulto. Eran empleados por los aztecas para ofrecerlos como sacrificio a sus dioses. 
a la fluctuación narrativa que ha sido mencionada, uno de los ajolotes de Mauricio se convierte en salamandra; uno de "los cuerpos fríos que flotaban sin gracia, prehistóricos, inalterables" (86) muta en salamandra, deja de ser un estado indefinido, una eterna posibilidad vacilante para convertirse en una forma cierta. La ambivalencia de Mauricio sigue a la presencia concreta de la salamandra como una antelación de la posibilidad de ser en el mundo de este personaje; la fatalidad de no llegar a ser, de no tomar nunca una forma definida, materializada en el axolotl, desaparece en la salamandra que reposa junto al cuerpo desmayado de la madre de Mauricio y, luego, en la voluntad de éste para elegir su propio proceso de "maduración": "Mi modelo evolutivo eran los ajolotes de Terminal Progreso que podían mutar con el yodo y el agua salada" (123).

La salamandra es, entonces, producto del yodo y el agua salada, es decir, no de un destino inalterable, sino de una decisión personal; el mundo -sus verdades-no es para Mauricio una entidad incuestionable, sino una realidad movible que exige constante reinterpretación; lo mismo el hecho de "llegar a ser". La "madurez" en Mauricio no se define por el estado inalterable que puede alcanzar un ser humano; aquí la forma definida es la realidad de incertidumbre en la que está inmerso el personaje, la elección de vivir en ella y aceptar la dispersión que se produce allí y que se presenta como "materia dispuesta" ante la mirada del testigo (no de aquel que se entrega total y confortablemente, inconscientemente, a esa realidad).

Si en un principio la axiología de Mauricio parece encarnar la "gratificación sin consecuencias" de la Modernidad líquida, a lo largo de la novela este sentido apenas permanecerá en la superficie, puesto que resultará tan sólo un pretexto para instaurar al personaje como ser crítico frente a la tradición, es decir, como un ser dispuesto a asumir una mentalidad postmoderna; en Materia dispuesta, Mauricio se contrapone a la figura de su padre en cuanto puede concebir de modo distinto la axiología moderna (sólida) que él encarna (a través de la desconstrucción de la noción de destino moderno), después de percibir las inconsistencias presentes en esa axiología -y, así mismo, en la época en la que se instituye como proyecto-: "Jesús Guardiola parecía no 
tener otra ambición arquitectónica que ampliar cocheras y ganar lo suficiente para complicarse la vida. Ninguno de nosotros sospechó los cambios que se gestaban en su interior. Un día llegó fuera de sí, con una felicidad inédita: le había pasado algo bueno que no tenía que ver con su cuerpo" (42).

Jesús Guardiola es un hombre infiel, quien usa las salidas con su hijo menor para conocer posibles amantes, que sueña con París, pero ingresa a la Escuela Mexicana para realizar construcciones nostálgicas del esplendor prehispánico azteca, como una manera de recuperar los valores nacionales -y mejorar su situación económica-:“El arquitecto mexicanista soltaba datos que nos rebasaban; en rigor, no se dirigía a sus tres parientes más cercanos sino a sí mismo; buscaba, en forma casi desesperada, convencerse de algo que apenas conocía" (44), y más adelante: "Yo [Jesús] busqué y encontré, busqué y encontré. [...] Pasa lo mismo contigo; te sales del camino, te desvías y das con algo que era tu meta sin que lo supieras [...]. Supongo que todo destino es eso, una desviación propicia" (287). El destino como "desviación propicia" pone a Jesús Guardiola en el plano de la Modernidad sólida ${ }^{13}$, en cuanto sigue interesado en reconocer en toda elección un camino trazado y propio, hallado como una afirmación de sí mismo.

En el mismo sentido de las inconsistencias axiológicas mencionadas, se encuentra el hecho de que en su segundo matrimonio, Jesús elija como esposa a una mujer extranjera (inglesa) que considera a México como un "país mágico, iy un pelín surrealista!" (187), confirmando, así, su posición frente a lo que considera los valores nacionales; el arquitecto que necesita convencerse de su mexicanidad, busca una mujer que confirme su singularidad a partir de evaluaciones nacionalistas -exotistas- adjudicadas desde una mirada extranjera: la del turista, quien exige que lo mexicano demuestre ser mexicano, que defienda su singularidad, si es posible, exagerando sus particularidades hasta convertirlas en simple adorno.

13 Aunque en vías de degradación, dadas las huellas de incoherencia entre sus principios y sus acciones, su falsa moral. 
Roberta abandona a Jesús cuando el proyecto de un jardín que recordaba el esplendor azteca, a manera de parque recreativo, es anulado al encontrar ruinas aztecas subterráneas en el mismo lugar donde se llevaba a cabo dicho proyecto, convirtiéndolo en zona arqueológica. Jesús sufre un infarto y decide viajar a Estados Unidos para someterse a una operación tras de la cual es criticado por la Escuela Mexicana -por traición a los valores nacionalistas-, al tiempo que su mentor es expulsado de ella y de su puesto en la gobernatura; después muere. El final de Jesús Guardiola constituye un aspecto de la crítica que se realiza al "rescate" de los valores nacionales: "Detrás de esas construcciones patrióticas se revela toda una trama de corruptela en la que se dan, o mejor, se untan la mano la inversión inmobiliaria y el politiqueo. A partir de ahí es tan sólo cuestión de empatía ver o no ver una alegoría grotesca del México actual en el provechoso uso de los sagrados ancestros aztecas y de la aún más sagrada palabra Patria, en la capacidad del gobierno "para combinar los valores nacionales con los ladrillos" (Mihály, 2005, 3-4) como si la construcción artificial de símbolos sagrados pudiera recuperar el pasado, o mejor: como si la reconstrucción del pasado fuera una honesta posición frente a la defensa de lo propio y no una manera de sacar provecho económico de las ansias de mestizaje del Primer Mundo y de sostener la imagen del Estado y su proyecto nacionalista.

En este punto es necesario centrarse en la actitud de Mauricio ante el trabajo de su padre como "rescatista" del pasado mexicano: "Cuando mi padre empezaba con sus peroratas de gurú nacionalista, yo corría a refugiarme en mi colección de basuras. En ocasiones me seguía por el pasillo, me tomaba de la oreja [...] y me obligaba a regresar a la mesa donde se discutía la traición de los tlaxcaltecas" (48). Esa "colección de basuras" incluye obsidianas recolectadas en los alrededores de su casa, cerillos, botones, un silbato, "Io suficiente para suponer una conexión entre ellos, y para que esa conexión no fuera lógica" (39): "la riqueza de la basura está en su dispersión" (38); la basura (dispersa) de Mauricio constituye una posición crítica frente a la unidad nacionalista que presuponen los proyectos arquitectónicos de su padre y sus argumentos puristas de lo que es lo mexicano, la posibilidad que ofrece la Postmodernidad de permitir la existencia de lo fragmentado, 
de lo diverso e híbrido. A pesar de que Mauricio aún sienta vigente esas necesidades modernas de la totalidad y el progreso ${ }^{14}$, lo que impera en él es su actitud transgresora frente a los valores defendidos por su padre y su madre (Cristina Ferrán), personificando, esta última, valores pertenecientes a la premodernidad, a una sociedad netamente conservadora y católica: "Mamá [...] admiraba el trabajo duro y sentía que todo estaba bien cuando la noche encontraba a la familia exhausta. Mi padre se quedaba dormido sobre sus planos en papel albanene y ella sonreía como no lo había hecho en mucho tiempo convencida de que la virtud cansa" (43).

\section{La transgresión como elemento dinamizador del héroe}

Mauricio se opone a unos valores impuestos, aprendidos en los libros que consulta su padre para sustentar su pasión nacionalista, así como también se opone a unos valores que imponen la dominación del cuerpo, los buenos modales, el desdén ante la moda y la expresión de las emociones, y el mantenimiento de un orden incuestionable defendido por su madre. A través de un comportamiento que va en contravía a la educación recibida en su casa, Mauricio se enamora de una mujer que contradice todos los cánones de belleza y comportamiento "femenino" $\left(\right.$ Verónica $\left.{ }^{15}\right)$, su experiencia sexual se

14 Materializadas en las conexiones no necesariamente lógicas otorgadas a sus actos, pero que dan sentido a su existencia, en la posibilidad de futuro que se plantea al final de la novela y en el desarrollo de los personajes de la misma: Jesús se convierte en un prestigioso arquitecto -aunque luego pierda su posición social-; Carlos llega a ser un respetable abogado; su mamá consigue empleo y aprende a conducir -aunque siga tratando a su ex-esposo y a sus hijos con la misma entrega sumisa-, Verónica estudia Microbiología y logra un trabajo en la Estación de Floricultura; el mismo Mauricio logra reconocimiento por su trabajo como camarógrafo -aunque siempre desprecie los trofeos- y consigue un apartamento en el centro de México, apartándose, así, de la periférica zona de Terminal Progreso, donde vive el resto de su familia. Aquí puede observarse también cómo los personajes fluctúan entre opciones axiológicas contradictorias, afirmando la orientación de la novela a presentar la realidad como un espacio híbrido y al mismo ser humano como heredero de esa hibridación.

15 Verónica, a pesar de todos los infortunios que ocurren en su vida (permanece en coma desde su niñez hasta su adolescencia, después de ser atropellada por un automóvil)), jamás asume la posición de víctima; su opción es actuar en el mundo, integrada a su presente:... (sigue) 
inicia a partir de relaciones con seres de su mismo sexo-incluyendo el gusto por los superhéroes de los comics y las estampas de la hagiografía cristiana: su mezcla de valentía, dolor y erotismo-, consume "mariguana" y desprecia los trofeos. Estos comportamientos pueden ser interpretados a través del fenómeno social y contracultural de la Onda, del cual Carlos Monsiváis afirma que "no viene de reflexiones y teorías sino de la negativa ante el cielo de valores fijos" (Mosivais, 2003, 230); Mauricio personifica esta oposición a esos valores fijos, influenciada por la"norteamericanización" cultural desarrollada en las décadas del sesenta y setenta en Latinoamérica.

La Onda se opone al mundo burgués (moderno) en cuanto propone el "aliviane", la licuefacción de los imperativos de la Modernidad sólida (razón, progreso social); "es el primer movimiento del México contemporáneo que se rehúsa desde posiciones no políticas a las concepciones institucionales y nos revela con elocuencia la extinción de una hegemonía cultural. Tal hegemonía se surte, en términos generales, en la visión gubernamental de la Revolución Mexicana y se concreta en el impulso nacionalista [...]. El nacionalismo cultural se impuso desde arriba" (Mosivais, 2003, 235) y ante esto la Onda construye opciones culturales que se oponen a los valores no asimilados por esa generación que inaugura la segunda mitad del siglo XX y que ya se han añadido al patrimonio de la burguesía (novela de la Revolución Mexicana, redescubrimiento del arte prehispánico) como baluartes de sus intereses personales.

Sin embargo, la Onda presenta una contradicción, pues al aparecer como "hambre de contemporaneidad", los “jipitecas fracasan al no captar que a la imitación no se le opone la imitación en un medio donde el proceso colonial

15 (viene) ...."[Verónica] era lo contrario a las mujeres que se pintaban las uñas de los pies [...], es decir, a las que vivían para irse. Verónica estaba allí, dispuesta a luchar por plantas próximas. Se vestía como un muchacho, una camiseta cubría sus senos sin relieve, sus zapatos estaban enlodados y casi siempre tenía briznas en el pelo; todo en ella apuntaba al esfuerzo, a la dedicación sin placeres evidentes" (249). En este sentido, se puede entender su cercanía con Mauricio, en tanto la transformación de éste después de la mitad de la novela y su actitud de desafío ante unas maneras de comportamiento social conocidas y aceptadas; ambos personajes encarnan la posibilidad de actuar en el mundo en un aquí y ahora desde sus particulares elecciones y actitudes para responder a esa realidad dispuesta. 
[y de modernización] ha ido de la admiración elitista por la cultura [española,] francesa o inglesa a la admiración multitudinaria por Norteamérica" (Mosivais, 2003, 237); la Onda como movimiento contestatario se reifica al dejarse asimilar al sistema del que pretenden desertar -como ocurrió con las vanguardias artísticas de principios de siglo XX-, imposibilitando la demostración de la falsedad de los procesos de "progreso" cultural a través de la imitación, del afán de ponerse al día siguiendo modelos extranjeros. No obstante, aunque la Onda terminó siendo un repertorio de sensaciones fuertes para la burguesía y para los massmedia, su influjo en la sociedad es importante en cuanto al cuestionamiento que hacen a la tradición, al convertirse en protagonistas de actitudes que evidenciaban las inconsistencias de una "identidad nacional" que ya no correspondía a la mentalidad de sus representantes.

Mauricio Guardiola, al mantenerse en una posición crítica hasta el final de la novela, se configura como una entidad que no cae fácilmente en las categorizaciones, en la asimilación de sus posturas críticas por parte de la sociedad burguesa que aminoraría su poder de cuestionamiento. En Materia dispuesta, la actitud "alivianada" de Mauricio no desemboca en la indiferencia axiológica -propia de la Modernidad líquida-; por el contrario, el final de la novela alude a esa posibilidad de actuar, de responder a las exigencias de la Historia y de configurarse como un personaje axiológicamente dispuesto a asumir la incertidumbre de la sociedad actual, a seguir intentando recoger porciones dispersas, escombros, y otorgarles un sentido que le permita concebir su mundo como una forma -entre muchas otras posibles- de totalidad, como una modo de contención posible, de actuación posible. Juan Villoro, al recrear el terremoto de 1985, al retomar un hecho histórico de gran importancia para la población mexicana, afirma la importancia y vigencia de valores que en ese momento fueron imprescindibles para superar la situación y para empezar a salir del letargo político en el que estaba sumido el país ${ }^{16}$, fortaleciendo los deseos y las posibilidades de actuar y de influir en el ordenamiento del

El PRI revelado como sistema impotente para resolver las necesidades del país y que, sin embargo, acallaba las propuestas de cambio provenientes de la población civil, lo que provocaba una actitud pasiva en toda la sociedad mexicana, la renuncia a producir una resolución, una alternativa. 
espacio público (político, económico y social), de tener consciencia como seres humanos del devenir histórico del que también se es responsable.

En este aspecto reside la importancia de la configuración del "héroe novelesco" en Materia dispuesta, pues al proponerse como un personaje que actúa frente a la inminencia de la Historia (el terremoto que marca el final de la novela y en el cual él y Verónica se asumen como brigadistas), alude a la posibilidad de introducir un cambio en ella. El terremoto como metáfora de un espacio inestable ante el cual los seres humanos deben responder, permite entender aquello que denomina Bajtín como "novela de desarrollo del hombre"; en Materia dispuesta, el héroe se encuentra axiológicamente ubicado entre dos épocas (Moderna y Postmoderna), y al vivir en sí mismo una transición histórica, se propone como un ser estrechamente relacionado con la temporalidad, es decir, consciente de su situación en el mundo y de su necesidad de plantear su presente respecto a ella.

\section{Mauricio Guardiola y la novela de desarrollo}

Cuando Bajtín plantea el problema de la novela de educación, describe la novela en la que el protagonista es un "héroe preconcebido e invariable"; junto a este tipo de novela aparece otro que ofrece una imagen del hombre en proceso de desarrollo:

En oposición a la unidad estática, en este tipo de novela se propone una unidad dinámica de la imagen del protagonista. [...] La transformación del propio héroe adquiere una importancia para el argumento, y en esta relación se revalúa y se reconstruye todo el argumento de la novela. El tiempo penetra en el interior del hombre, forma parte de su imagen cambiando considerablemente la importancia de todos los momentos de su vida y su destino. Este tipo de novela puede ser denominado, en un sentido muy general, novela de desarrollo del hombre (Bajtin, 1985, 212). 
Este hombre en proceso de desarrollo es personificado por Mauricio Guardiola en Materia dispuesta, pues en ella el héroe no está configurado desde el principio y se mantiene inmutable hasta el final, correspondiendo a la idea de un destino épico (el hombre cuyas hazañas son una demostración de un destino trazado de antemano) o uno moderno (el hombre cuya aventura en el mundo constituye un proceso de adaptación y madurez, a través del cual se forja a sí mismo), sino que su desarrollo estará asociado al devenir histórico, a sus procesos de transgresión y desdibujamiento de la noción moderna de destino. Dentro de este tipo de novela, Bajtín establece una subclasificación en la cual se encuentra la que él denomina como "novela realista de desarrollo"; en ella:

El hombre se transforma junto con el mundo, refleja en sí el desarrollo histórico del mundo. El hombre no se ubica dentro de una época, sino sobre el límite entre dos épocas, en el punto de transición entre ambas. La transición se da dentro del hombre y a través del hombre. El héroe se ve obligado a ser un nuevo tipo de hombre, antes inexistente. [...] La fuerza organizadora del futuro es aquí, [...] muy grande (se trata de un futuro histórico, no de un futuro biográfico privado). Se están cambiando precisamente los fundamentos del mundo, y el hombre es forzado a transformarse junto con ellos (Bajtin, 1985, 215).

Lo anterior es lo que precisamente se ha observado en la formación de Mauricio Guardiola como "héroe novelesco" de Materia dispuesta; al estar en la transición de la Modernidad sólida a la líquida, Mauricio asume el proyecto de una mentalidad postmoderna como responsabilidad moral en medio de la incertidumbre axiológica que caracteriza la época actual. Sus cambios obedecen a la búsqueda de un nuevo centro (entendido como posibilidad de redondeamiento vital, de sentido, y no como una posición hegemónica), en consonancia con los procesos de cambio ocurridos en la sociedad a la que pertenece. Sin embargo, debe aclararse aquí, que para el caso Latinoamericano esa transición histórica presenta más tangiblemente que en otros lugares del mundo, una confluencia de temporalidades: Premodernidad, Modernidad y Postmodernidad. 
El hecho de ser conquistados por España influye para que en América Latina los procesos de modernización y Modernidad se den de modo más lento que en otros países de Occidente, al estar profundamente influenciados por la moral cristiana impuesta por la Iglesia Católica y por sus instituciones represivas, las cuales, de otra parte, construyeron sus ciudades sobre las culturas prehispánicas. Además, este proceso de modernización se ha desarrollado siguiendo modelos extranjeros, lo que no permite asimilar los cambios, sino adoptarlos de manera inconsciente a la realidad latinoamericana; ahora, por ejemplo, se podría hablar de un proceso de postmoderniza-ción, especialmente a partir de la "norteamericanización" de la que ya se ha hablado anteriormente $y$, sobre todo, de la influencia de los massmedia.

Mauricio Guardiola, al proponerse como un testigo que recoge porciones dispersas, alude a esa fusión de temporalidades latinoamericanas, a la probabilidad de vincular en sí mismo de manera consciente la hibridación como una realidad incierta -no indefinida- que permita el alejamiento de posiciones nostálgicas frente a un pasado prehispánico perdido y frente a la misma ciudad moderna semidestruida después del terremoto, y también de posiciones fatalistas que obstaculicen la problematización de la tradición y permanezcan en definiciones petrificadas del ser nacional. Para Mauricio el pasado prehispánico que enarbola su padre en sus construcciones arquitectónicas: "No se trata de unas ruinas muertas, aunque pintorescas, que no tengan ninguna relación con la viva actualidad circundante y que carezcan de toda influencia sobre la realidad. [...] Aborrecía las ruinas, esas envolturas externas de un pasado desnudo propias de un museo o de una tienda de antigüedades" (Bajtin, 1985, 224).

Si el pasado sólo sirve como adorno, entonces no tiene nada que decir al presente, pero en el caso de Materia dispuesta, el pasado se yuxtapone al presente, no de manera artificial, sino concreta, recordando que los valores no se recuperan, sino que están allí, de manera cotidiana y visible en el paisaje y en los gestos que constituyen la manera de relacionarse con él ${ }^{17}$. De esta manera, en la novela, el pasado y el presente se encuentran en una relación estrecha en donde se puede vislumbrar un futuro posible. No hay 
una nostalgia por el pasado; por el contrario, las "ruinas" del pasado se considerarán como signos del tiempo que transcurre, como parte de todo lo que necesariamente perece, pero que, al mismo tiempo, permite la creación de algo significativo. En este sentido, es tangible aquí la confianza en el proyecto de la Modernidad, en tanto el terremoto se transforma en la oportunidad de construcción, de acercarse "al borde de las cosas, a lo que empieza a ser distinto, futuro, definitivamente real" (311), como afirma la frase final de la novela; hay en Villoro -en esta novela- una confianza en el ser humano, en sus posibilidades de desarrollo axiológico responsable en concordancia con su devenir histórico.

\section{Identidades espaciales: terremotos en la megalópolis}

En este apartado se mostrará cómo el espacio y el tiempo en Materia dispuesta constituyen otra unidad importante para hallar el sentido de la novela. Si la constitución del héroe novelesco obedece a una axiología de transición entre la Modernidad y la Postmodernidad, el espacio y el tiempo en el que se desarrollan los acontecimientos, también serán materialización de esta axiología.

La reconstrucción de la anécdota pone en un primer plano de significación el hecho que su inicio y su final estén marcados por terremotos; Mauricio Guardiola nace en 1957, año de uno de los terremotos que sacudió a México

17 Esto es visible en dos aspectos concretos de la novela: el primero lo constituye el hecho que el parque alusivo al pasado azteca, construido por Jesús Guardiola, sea frenado por el hallazgo de una parte de Tenochtitlán debajo de la construcción que se estaba realizando; el segundo consiste en que Verónica y Mauricio pasen su primera noche juntos en una casa museo de principios del siglo XX sobre el final de la novela. Aquí es claro cómo el presente no puede anular el pasado reciente o lejano, sino que ellos coexisten en una misma temporalidad que afecta aún a los personajes, a su mundo. 
tras el cual la familia Guardiola debe mudarse de la Colonia Roma (ubicada en el centro tradicional de la ciudad) a Terminal Progreso, una unidad urbanística construída en las afueras de la ciudad junto a los canales de Xochimilco, "lo único que quedaba del lago de los aztecas. Aquel paraje era un híbrido sin gloria; la ciudad sitiaba al campo sin derrotarlo y llegaba a nosotros en forma precaria" (29), según la percepción de Mauricio. La novela termina el día siguiente al terremoto de 1985 que, de manera mayoritaria, produce la destrucción del centro de la ciudad y a partir del cual se propicia lo que Juan Villoro explica como:

Un nuevo trato con la urbe. En un sentido político y comunitario, permitió que la población se organizara en forma espontánea para responder a la tragedia ante la inoperancia del gobierno. Un nuevo rostro ciudadano surgido entre los brigadistas que buscaban ordenar las piedras rotas. Hubo miles de muertos y desaparecidos, pero también se fraguó un sentido de la resistencia hasta entonces inédito. Poco a poco, comenzó a hablarse del "partido del temblor", la masa crítica que sacaría al Partido Revolucionario Institucional (PRI) del gobierno de la capital (Villoro, Espectros de la ciudad, 2006, VI).

Lo que reveló el terremoto de 1985 fue que el gobierno mexicano (representante institucional de la Revolución Mexicana) no podía suplir todas las necesidades de la población -como fue evidente desde 1968 con el asesinato, por orden del gobierno, de estudiantes que protestaban en la Plaza de Tlatelolco- $y$ ante esto, la colectividad se organizó, actuó para responder a una situación que exigía el trabajo grupal y la solidaridad, "la experiencia del terremoto le dio al término sociedad civil una credibilidad inesperada. [...] Mucho se avanza cuando los ciudadanos-en -vías-de-serlo dejan de esperarlo todo del Presidente" (Monsivais, 2001, 13).

Hay, aquí, una relación entre lo explicado anteriormente acerca de Mauricio Guardiola, configurado como un héroe de la novela de desarrollo, y la noción temporal que construye el texto novelesco: los terremotos remiten a la noción de transformación, de un cambio inminente, constituyen huellas de 
una temporalidad como condición necesaria para que se produzca la transición de una época a otra o de una etapa a otra, vislumbrando, así, un futuro posible ${ }^{18}$. En Materia dispuesta, los escombros, al igual que las "ruinas" del pasado prehispánico, son signos del transcurrir del tiempo, los cuales exigen una actuación en el mundo en un aquí y un ahora, permitiendo recuperar una utopía colectiva, cuestionar un orden anterior y la noción de progreso que se proponía desde él, pues resulta ya ineficiente para el momento actual, al desvelarse las inconsistencias y simulacros de su proyecto; en la novela, el testigo -Mauricio Guardiola, pero también Verónica- se convierte en brigadista: recoge trozos dispersos, buscando "ordenar las piedras rotas", intenta centrar lo descentrado como actividad de interpretación constante del mundo inestable que habita-incorporando sus particularidades y exigencias espacio-temporales concretas-, jamás como asimilación de la realidad como un todo incuestionable:"Al ver los afanes dispersos, las manos seleccionando las ricas basuras, Mauricio sintió que todo encajaba de otro modo" (311).

\section{La pirámide y la problematización de la identidad mexicana}

Los años cincuenta corresponden al período de Posguerra durante el cual comenzó a sistematizarse la crítica contra la Modernidad, haciendo de la "cultura periférica una trinchera de resistencia ante los males de la modernización con lo cual quedamos en el mismo lugar en el que ya nos había puesto Hegel: fuera de la Historia. [...] Dispensar a las culturas periféricas de su inclusión en la modernidad es otra manera de excluirlas, cuando lo que se requiere es pensar las maneras conflictivas y desgarradas, incluso sangrientas, de su inclusión en ella" (Grüner, 2002, 263-264); lo anterior es a lo que Villoro

18 Las obsidianas recolectadas por Mauricio también son huellas de esa temporalidad, en cuanto cada una constituye un "cronómetro absoluto" (44), pues su "línea de humedad" permitía leer el tiempo en ella, su edad. Estos elementos son transversales en la historia hasta el final: "Los testigos que recogían las porciones dispersas, rotas: una naranja un y eso una llave un botón una piedra un alfiler una obsidiana" (311). La condición temporal de la existencia humana será encarnada por este objeto disperso en la "colección de basuras" de Mauricio; su importancia no está en el pasado azteca (flechas de obsidiana), sino en el devenir histórico percibido por Mauricio en su aquí y ahora. 
denomina como "utopía del atraso": "Estamos ante un colonialismo de nuevo cuño, que no depende del dominio del espacio sino del tiempo. En el parque de atracciones latinoamericano, el pasado no es un componente histórico sino una determinación del presente. Anclados, fijos en su identidad, nuestros países surten de antiguallas a un mundo que se reserva para sí los usos de la modernidad y del futuro" (Villoro, Iguanas y dinosaurios: América Latina como utopía del atraso, 1990, 26). En Latinoamérica el proceso de Modernidad se ha dado, sobre todo, a partir de los mecanismos de modernización, es decir, de lo que se ha explicado ya como una pulsión de ponerse al día a través de la imitación, la implemen-tación de tecnologías novedosas o la adopción de modas, pero la Modernidad como proceso de secularización no se ha dado completamente; de esta manera, se tiene que la situación de Latinoamérica durante la Modernidad y la ahora llamada Postmodernidad, sigue signada por la exclusión y la dominación, ya no de su territorio -de forma explícita-, sino de sus imaginarios - de su temporalidad o sentido histórico-.

La forma en la que los países del Primer Mundo ejercen esta dominación de los imaginarios, es visible en Materia dispuesta a través de la noción de identidad y exotismo: "El mexicano es, para el discurso identitario, un ser incompleto. Constitutivos de este canon son un sentimiento de melancolía frente al pasado perdido y al presente no dominable, y la idea de metamorfosis. Como el axolote, el mexicano se transforma, pero no alcanza adultez ni madurez" (Dussel \& Morales, 2) ${ }^{19}$. El exotismo propicia una "autenticidad artificial" que obliga a una cultura a señalar continuamente su singularidad y a exagerarla para ser reconocida por la mirada del turista, por la mirada extranjera; en la novela este aspecto de la cultura Latinoamericana -y su crítica- es visible en tres elementos: Jesús Guardiola y la arquitectura que intenta "rescatar"valores prehispánicos, los ajolotes de Mauricio, la segunda esposa de Jesús (Roberta Archer), el parque que quiere construir el padre de Mauricio a partir de figuras aztecas y la obra de teatro en la que participa Pancho -amigo de Mauricio-: Abraxas.

19 Sin embargo, en Materia dispuesta, el axolotl es una figura transgresora en esta concepción de la identidad mexicana -como ya se ha demostrado-, puesto que en la novela éste sí llega a convertirse en salamandra. 
Ante estos elementos que configuran una identidad mexicana exótica, que propenden por la constitución y sostenimiento de una nacionalidad como parte de un proyecto moderno que pretendía una totalidad abstracta y cuyo efecto es el desligamiento del devenir histórico y la subsiguiente dominación extranjera, Mauricio Guardiola se propone como crítico: "Carlos y yo sabíamos que el mundo se dividía en mexicanos y turistas, pero jamás cruzó por nuestras mentes que tuviéramos que demostrar de qué lado estábamos. [...] No bastaba con haber nacido en la república de las serpientes y las aguas frescas, teníamos que parecernos a nosotros mismos, y celebrarlo a voz en cuello" (43), y más adelante cuando Pancho imita al promotor de la obra teatral: "A nadie le importa que los noruegos parezcan suecos o los finlandeses húngaros, pero nosotros no podemos negar la cruz de nuestra parroquia [...]. De nada sirve darle a los europeos lo que ellos también hacen" (282-283). En estas dos citas surge, entonces, la cuestión de lo absurdo que resulta tener que demostrar lo que se es, y en lo que puede derivar la "afirmación" de lo nacional cuando se usa como mecanismo de marketing -la identidad como parque temático-; la "modernidad mestiza" de Latinoamérica se convierte en un objeto intercambiable, garantía de la aceptación mundial de una singularidad anquilosada en el tiempo, en el pasado, aspecto que la mantiene fuera de la Historia, de su reinterpretación, de su presente, para tranquilidad del Primer Mundo. De este modo, el mestizaje, la hibridación (Cf. García Canclini, 1990,) como condición de la temporalidad latinoamericana (yuxtaposición de Premodernidad, Modernidad y Postmodernidad), perderían su razón de ser al terminar asimilada por las sutiles dinámicas del colonialismo en la Postmodernidad.

Mauricio Guardiola va en vía contraria a lo anterior, en cuanto su concepción de hibridación no pretende constituirse en una nueva unidad, en una totalidad absoluta, sino que ésta se ubica en la fragmentación, en lo disperso que invita a la interpretación y a la búsqueda constante de sentidos, siguiendo, así, la recomendación de Octavio Paz: "Ante las agitaciones y convulsiones del quinto sol, no serán la estabilidad, la solidez y la dureza de la piedra las que nos preservarán sino la ligereza, la flexibilidad y la capacidad para cambiar. La estabilidad se resuelve en petrificación" (Paz, 2005, 65); para Mauricio 
Guardiola, la identidad es un concepto abstracto que no permite asumir el presente, sumiendo al ser humano en un estado nostálgico que funciona como consuelo, pero no como forma de actuar en el mundo, dejando este rol de actores sociales a otros y a sus estrategias de dominación:"Por alguna razón, el público requería de una reserva de nostalgia, una prueba de que mejorar significaba retroceder; los desafíos nacionales no ameritaban inventos sino recuperaciones: el retorno de los días grandes en que los toros envestían con más fuerza, el cine ofrecía íconos que respiraban y la arquitectura era más tradicional, más típica, ¡más lo de uno!" (290).

La posibilidad de recuperar la tradición prehispánica, aunque haría parte de la apertura postmoderna, en Materia dispuesta se propone como la reproducción de un orden moderno (legitimar un proyecto nacional), por eso Mauricio será su crítico. La crítica de la Modernidad implica un examen de lo que significó y significa todavía la visión azteca del mundo y del orden impuesto desde ella, luego por las instituciones coloniales y después por los presidentes de la República, cimentado en una razón instrumental, de dominación, la cual puede rastrearse -según Paz- desde el período prehispánico y se ha desarrollado hasta la época actual a través de la reproducción de una organización jerárquica opresora:

La crítica de México y de su historia [...] debe iniciarse por un examen de lo que significó y significa todavía la visión azteca del mundo [...]. El punto de vista de los antiguos dioses y de sus servidores, los señores pontífices aztecas. Asimismo el de sus herederos y sucesores: Virreyes, Altezas Serenísimas y Señores Presidentes. [...] El punto de vista de la inmensa mayoría, las víctimas aplastadas por la pirámide o sacrificadas en su plataforma-santuario. La crítica de México comienza por la crítica de la pirámide (Paz, 2005, 259).

Esta crítica será visible en Materia dispuesta a través del cuestionamiento a la recuperación de la arquitectura prehispánica -expresión de una nostalgia mercantilizada-, pero también a esa ciudad moderna ideada por el orden colonial y construida sobre la ciudad azteca para demostrar su poderío, per- 
mitiendo la existencia de vestigios de Tenochtitlán, pero sólo como adornos, souvenir de un tiempo pasado que importa porque ya no puede volver y que se convierte en consuelo melancólico, en un pretexto para no asumir el presente. Terminal Progreso es una muestra de este ordenamiento urbano moderno: los antiguos canales aztecas (Xochimilco) se relegan a la periferia de la urbe; la ciudad moderna quiso ocultar la memoria del agua sobre la que estaba construida Tenochtitlán y, por otro lado, idea una ciudad que va dejando fuera de sí, las capas sociales menos adscritas al nuevo orden capitalista generalizado.

Terminal Progreso resulta un oxímoron de la Modernidad mexicana: la promesa de un progreso social se transforma en la consciencia de ser los residuos de un sistema -manifestado en el ordenamiento urbano- que va dejando por fuera a aquellos que no pueden responder a sus nuevas dinámicas; sin embargo, en la novela, es desde allí que se generan las críticas a ese orden impuesto sobre las ruinas aztecas y luego sobre las ruinas coloniales, confirmando la siguiente aseveración de Paul Virilio: "Se puede decir que la energía de las sociedades hiperestructuradas se refugia siempre fuera de ellas mismas. [...] De la confusión entre el bien y lo perfecto nace la producción del desecho. Es banal recordar que el espíritu de 1789 nacerá del de los libertinos y sectarios del siglo precedente" (Virilio, 1999, 43). Aquellos que son rechazados por el sistema, pueden construir una mirada distanciada, crítica -la mirada del testigo- sobre éste, como una forma de la resistencia, de la no asimilación inconsciente de las nuevas dinámicas, proponiendo una alternativa para afrontar su presente desde lo residual, lo disperso y fragmentado de su situación.

Las "campañas profilácticas" de la ciudad, en Materia dispuesta, son contundentemente cuestionadas a través de la recreación ficcional del terremoto de 1985; si bien es cierto que la licuefacción de la Modernidad sólida se venía desarrollando desde los años sesenta -a través de la Onda-, es sólo después del terremoto que se puede vislumbrar una mentalidad postmoderna que asuma la responsabilidad moral en una sociedad rota. La destrucción del centro de la ciudad de México y sus edificios de construcción más reciente, 
aluden a la necesidad de pensar un nuevo ordenamiento urbano-social, pero también de vincular a ese orden la Historia, aquello que se mantiene incólume en ella, como la evidencia de una temporalidad que no anula lo que aún hace parte de una concreta manera de ser; en Materia dispuesta la yuxtaposición temporal es consciencia de un ser histórico que no puede abstraerse de su devenir y que, por eso mismo, puede realizar su crítica a éste, actualizando y reinterpretando su sentido.

Esto último tiene que ver con el final de la novela, cuando Verónica y Mauricio pasan la noche en una casa-museo de principios del siglo XX, luego del terremoto: "Había quinqués en las mesas. En un rincón, la luz del sol inquietaba una vitrina. Mauricio se acercó a ver medallas, diplomas, cintas de colores, distinciones vagas. Estaba en una casa museo, no había duda. Probablemente aquellos cuartos honraban a un prócer menor, con descendientes adinerados, capaces de sacrificar una propiedad para perpetuar una gloria incierta con pergaminos, los rostros de las tías, muebles incómodos" (310). Este lugar resulta anacrónico ante los ojos de Mauricio, representante de un orden absurdo por artificial, pero, al mismo tiempo, le permite cuestionarlo a través del encuentro amoroso con Verónica allí; la casa-museo como espacio funcional (artificial) afirmador de un orden anterior anacrónico, se convierte en cómplice del amor consumado por los dos personajes transgresores en la novela. El amor como encuentro con un otro, como compromiso elegido con un otro, aparece en la novela como una afirmación más de la salida de la indiferencia axiológica que propone la Modernidad líquida ${ }^{20}$ y confirmación de la transformación de Mauricio: su desprendimiento de un mundo redundantemente subjetivo y su vinculación en él del mundo intersubjetivo, de su posibilidad de actuar en el mundo.

\footnotetext{
2o Época en la que imperan las ganas y el deseo, los encuentros efímeros, sin consecuencias, ni compromisos.
} 


\section{8. "La reveladora fuerza de las confusiones"}

La Arquitectura propone al hombre como homo faber, como constructor del espacio que desea dominar de acuerdo con el momento histórico en el que se inserta su proyecto, por lo cual su discurso se presenta en Materia dispuesta como configurador de la ciudad moderna en expansión, en camino firme de convertirse en megalópolis. Según Juan Carlos Pérgolis (1995), los movimientos arquitectónicos pueden clasificarse de acuerdo con dos lineamientos distintos: la Arquitectura utópica como un proyecto colectivo-nacional progresista que caracterizó al Movimiento Moderno, signado por la pulsión de construir, el cual fue muriendo después de la II Guerra Mundial, y los proyectos arquitectónicos que tienden hacia la expresión de lo individual con una clara intención funcionalista, los cuales son denominados por Pérgolis como "fantasías conservadoras", caracterizados por obedecer a la moda, al consumo y a lo desechable, en consonancia con la época de fragmentación en la que se produce.

En Materia dispuesta la ciudad de la Modernidad líquida busca transformar funcionalmente los espacios, tanto el espacio sagrado de la ciudad azteca -convertido en mercancía- como el espacio configurado por el proyecto moderno -convirtiéndolo en museo, por ejemplo- en pos de imponer nuevas maneras de moverse en la ciudad; pero el funcionalismo es contrarrestado por la realidad concreta (el devenir histórico como realidad que conlleva fuerzas del pasado aún vivas): las "ruinas" aztecas se interponen en la construcción de un parque recreativo sobre esta misma cultura prehispánica y el terremoto destruye los edificios de más reciente construcción, haciendo que los espacios transformen su función, como es el caso de la casa que sirve de refugio a Verónica y Mauricio, cumpliendo por lo propuesto por Paul Virilio:

Como los niveles del acostumbramiento constituyen el habitar, el funcionalismo es una tentativa desesperada de la arquitectura para intervenir en un espacio afectivo que no cesa de escapársele. [...] Fatalmente ideológico, el funcionalismo limita la intervención de las formas, las somete a interdictos, a tabúes [...]. Cada vez que se produce una gran crisis, un cataclismo o algún otro traumatismo social 
cualquiera, se asiste a una inflación de las transgresiones del uso [...]. La transgresión del uso es una subversión productiva que alimenta constantemente a la sociedad con costumbres nuevas y constituye la fuente de las transformaciones del espacio social (Virilio, 1999, 151).

El terremoto de 1985, su confusión reveladora, sucede a la muerte de Jesús Guardiola, lo cual posibilita un quiebre respecto al orden del padre, por parte de Mauricio; si en su infancia, éste pensaba que la causa de los temblores eran los pasos de su padre, al final de la novela, el terremoto le permite vislumbrar un cambio definitivo dentro del orden de lo real, un cambio relacionado con un futuro que no pretende volver atrás, sino que exige una nueva manera de relacionarse con la ciudad, con su tiempo.

\section{Bibliografia}

Bajtin, M. (1985). Estética de la creación verbal. México: Siglo XXI.

Bauman, Z. (2006). Modernidad líquida. Buenos Aires: Fondo de Cultura Económica.

Dussel, S., \& Morales, J. (s.f.). Pirámide, axalote y "crack" en la arquitectura mexicana reciente. Obtenido de www.mexartes-berlin.de/esp04/dussel-morales.html.

García Canclini, N. (1990). Culturas híbridas: estrategias para entrar y salir de la modernidad. México: Grijalbo.

Grüner, E. (2002). El fin de las pequeñas historias: de los estudios culturales al retorno (imposible) de lo trágico. Buenos Aires: Paidos.

Marina, J. A. (2000). Crónicas de ultramodernidad. Barcelona: Anagrama.

Mihály, D. (2005). Revista de Cultura Lateral. Recuperado el 2006, de www. lateral-ed.es.

Monsivais, C. (2001). Entrada libre: crónicas de la sociedad que se organiza. México: Era. 
Mosivais, C. (2003). Amor perdido. México: Era.

Paz, O. (2005). El laberinto de la soledad, Posdata, Vuelta al laberinto de la soledad. México: Fondo de Cultura Económica.

Pérgolis, J. C. (1995). Express: arquitectura, literatura y ciudad. Bogotá: Universidad Católica de Colombia.

Villoro, J. (2006). Espectros de la ciudad. En Número (50).

Villoro, J. (1990). Iguanas y dinosaurios: América Latina como utopía del atraso. En El Malpensante (15).

Virilio, P. (1999). La inseguridad del territorio. Buenos Aires: La Marca. 